\title{
Comparison of selected splines for stem form modeling: A case study in Norway spruce
}

\author{
K. Kuželka, R. Marušák
}

Kuželka K., Marušák R. 2014. Comparison of selected splines for stem form modeling: A case study in Norway spruce. Ann. For. Res. 57(1): 137-148, 2014.

\begin{abstract}
Natural cubic spline has been frequently used to represent stem forms, with other spline types rarely involved. Splines are a large class of functions and there are many other spline types which might serve that purpose. In this paper several different spline types, both interpolation and approximation, were investigated and splines more suitable for stem form representation than natural cubic spline are proposed. Their abilities to model the stem curve using different numbers of input points were compared using data of 85 carefully measured Norway spruce (Picea abies [L.] Karst.) stems. When modeling the whole stem profile all interpolation curves with second degree continuity suffer from oscillations. Approximation splines give satisfactory overall estimations, but they overestimate the lower stem and overestimate the upper stem. The best results were obtained with interpolation curves with first degree continuity. Stem curves were best described by the Catmull-Rom spline. Previously frequently used natural cubic spline performed worse than number of other splines. Keywords stem curve, taper model, interpolation, approximation, Norway spruce, diameter position.
\end{abstract}

Authors. Karel Kuželka (kuzelka@fld.czu.cz), Róbert Marušák - Department of Forest Management, Faculty of Forestry and Wood Sciences, University of Life Sciences in Prague. Kamýcká 1176; 16521 Praha 6 - Suchdol, Czech Republic. Manuscript received January 22, 2014; revised April 02, 2014; accepted April 09, 2014; online first April 11, 2014.

\section{Introduction}

Management of forests for timber production requires description of stem form and assessment of stem volume. During the last century, researchers have used a wide spectrum of approaches to represent the stem forms. Simple taper models of polynomial (Goulding \& Mur- ray 1976), logarithmic (Demaerschalk 1972), trigonometric (Thomas \& Parresol 1991), or sigmoid (Biging 1984) forms were initially used, but were later replaced by more complicated segmented models (Max \& Burkhart 1976, Jiang et al. 2005) or variable exponent models (Flewelling \& Raynes 1993, Lee et al. 2003), which are considered the most accurate 
(Rojo et al. 2005). Modern techniques of data acquisition such as terrestrial laser scanners (Lovell et al. 2011), close-range terrestrial photogrammetry (Dean 2003, Hapca et al. 2007), often require reconstruction of stem curve of an individual stem. The stem curve is modeled based on a number of measured diameters using methods of partial representation of stem curve segments with the use of interpolation and approximation techniques. A modeling technique suitable for the purpose are splines.

Spline is a general term for a large class of piecewise-defined polynomial functions. Two basic approaches to the construction of splines can be distinguished: interpolation and approximation (Linkeová 2007). The most known representative of interpolation splines is the natural cubic spline; a twice continuously differentiable interpolating curve consisting of cubic polynomials. The computational algorithm is well described by Smaltschinski (1983). The Catmull-Rom spline is an example of a class of important cubic interpolation splines that consist of Ferguson cubics. Only the first derivative of the curve is continuous which makes the curve more flexible (Kochanek 1984). Among approximation splines is important above all the B-spline. NURBS (non-uniform rational B-splines) are generalizations of B-splines. While the knot spacing of B-splines is always uniform, the knots of NURBS can be defined with any spacing or can be set by optimizing algorithms. All input points of B-splines are of equal importance; the relative importance of particular input points of NURBS can be weighted. Algorithms for computing the curves as well as their properties were well described by Piegl \& Tiller (1996) and Linkeová (2007). B-splines in the form of interpolation B-splines can also be used to interpolate data (Piegl \& Tiller 1996); in a different approach interpolation is achieved by iterative shifting of control points (Lin et al. 2004).

The interpolation cubic spline has been the spline most often used to describe stem form and to calculate stem volume (Goulding 1979,
Smaltschinski 1983). It has been demonstrated that better results can be achieved by using a monotony-preserving quadratic spline rather than cubic spline (Lahtinen 1988). Nevertheless, later works (Figueiredo-Filho et al. 1996, Laasasenaho et al. 2005) used cubic splines. Among other spline functions, the smoothing cubic spline was used to describe the stem form (Liu 1980) and later to predict the stem form in order to optimize cutting points for forest harvesters by Koskela et al. 2006.

The objective of this research was to compare the abilities of several different spline types to model the stem curve of Norway spruce using different numbers of input points.

\section{Materials and methods}

\section{Data}

This study used data from 85 Norway spruce trees (Picea abies [L.] Karst.). The trees were from three stands with ages from 50 to 100 years located in the School Forest Enterprise Kostelec nad Černými lesy, Central Bohemia Region, Czech Republic (49 54'30'N, $14^{\circ} 52^{\prime} 00^{\prime}$ 'E, $420 \mathrm{~m}$ a.s.1.). The area is covered by cambiosoils; with average annual temperatures $7.0-7.5^{\circ} \mathrm{C}$, total annual precipitation 600-650 $\mathrm{mm}$ and average vegetation period length of 153 days. The stands are even-aged pure plantations of spruce. In order to cover the shape variability dominant trees as well as suppressed trees were selected for the analysis. The diameter at breast height $(\mathrm{DBH})$ of the trees ranged from 88 to $438 \mathrm{~mm}$ (mean 204 $\mathrm{mm}$ ), and tree heights ranged from 10.6 to $37.1 \mathrm{~m}$ (mean $21.3 \mathrm{~m}$ ). The DBH-height relation of the sample is shown in Figure 1. Trees were felled and subsequently diameters outside bark were measured from the tree base to the top at $0.1-\mathrm{m}$ intervals. The distances from the tree base were measured using a steel tape with $0.01-\mathrm{m}$ precision, and the diameters were measured and recorded with an electronic cali- 


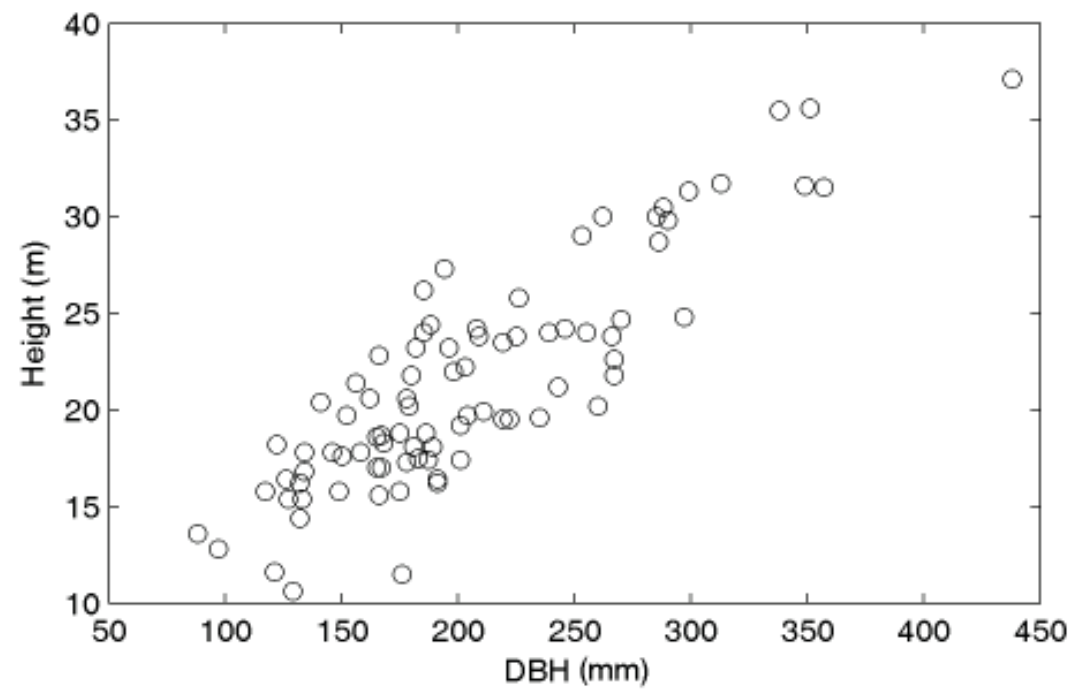

Figure 1 The DBH-height relation of the sample trees

per with 1-mm precision. Thus, several hundred diameters describing the stem form were obtained from each tree and were compared with the diameters predicted by splines.

\section{Splines}

All splines selected for the study are shown in Table 1. From interpolation splines, Catmull-Rom spline (CRS), natural cubic spline (NCS), interpolation B-splines with uniform parametrization of degree 2, 3 and 4 (IBS2, IBS3, IBS4) and iterative B-spline of degree 3 (IterBS) were selected. For all approximation splines, clamped curves, which exactly fit the first and last control points, were used. Four approximation splines (all variants of the second, third, and fourth degree) were tested: BS, NUBS; NURBSdbh, and NURBSav. BS denotes the B-spline with uniform knot spacing. NUBS is the non-uniform B-spline with the knot vector determined by averaging method, which optimizes the knot spacing when input points are unevenly distributed (Linkeová 2007). The third and the fourth variants were represented by NURBS with different weight distributions, both with averaging knot vector. In NURBSdbh, the relative importance of the input point representing the DBH was increased by setting its weight to 3 , while the weights of the remaining points were set to 1 ; this should improve the fit of the butt swell curvature. In NURBSav, the weights were set with an averaging algorithm that optimizes weight distribution so that the resulting curve passes all input points at relatively equal distances (Linkeová 2007). Numbers in abbreviations of spline types denote degree of each spline.

\section{Evaluation}

Nine input point sets were used. Each input point set contained a different number (2 to 10) of points (stem diameters) defined by their relative height on the stem plus four fixed points defined as follows: the stem foot $(\mathrm{h}=0 \mathrm{~m})$, the stump top $(\mathrm{h}=0.3 \mathrm{~m})$, breast height $(\mathrm{h}=1.3$ $\mathrm{m})$, and the stem top. Both the stem foot and the top must be involved to obtain the curve of the whole stem. The stump diameter is required for the proper description of the butt swell. DBH is included because it is a conventional parameter, and its value is always measured. Sets of relative heights representing optimal input point distributions for a given number of points for natural cubic spline (Table 2) were taken from Figueiredo-Filho et al. (1996).

The residuals between predicted and meas- 
Table 1 Specification of utilized splines

\begin{tabular}{lll}
\hline Sign & Spline type & Specification \\
\hline CRS & Catmull-Rom Spline & \\
NCS & Natural Cubic Spline & \\
IBSu2 & Interpolate B-spline & degree 2; uniformly spaced parameterization \\
IBSu3 & Interpolate B-spline & degree 2; uniformly spaced parameterization \\
IBSu4 & Interpolate B-spline & degree 2; uniformly spaced parameterization \\
IterBS & Iterative non-unif. B-spline & degree 3; number of iterations: 50 \\
BS2 & B-spline & degree 2; \\
BS3 & B-spline & degree 3; \\
BS4 & B-spline & degree 4; \\
NUBS2 & Non-uniform B-spline & degree 2; averaging knot vector method \\
NUBS3 & Non-uniform B-spline & degree 3; averaging knot vector method \\
NUBS4 & Non-uniform B-spline & degree 4; averaging knot vector method \\
NURBS2 & NURBS & degree 2; averaging knot vector, weight in DBH $=3$ \\
NURBS3 & NURBS & degree 3; averaging knot vector, weight in DBH $=3$ \\
NURBS4 & NURBS & degree 4; averaging knot vector, weight in DBH $=3$ \\
NURBS2aw & NURBS & degree 2; averaging knot vector, averaging weight distribution \\
NURBS3aw & NURBS & degree 3; averaging knot vector, averaging weight distribution \\
NURBS4aw & NURBS & degree 4; averaging knot vector, averaging weight distribution \\
\hline
\end{tabular}

ured diameters were assessed for each position of measured diameters. The accuracy of the predicted curves was evaluated with five statistical criteria computed for each stem (Table 3). Diameter bias (DB) indicates whether a modeled curve systematically under- or overestimates stem thickness. The mean absolute residual (MAR) reflects the average distance between the predicted and the original diameters. The standard deviation of residuals (SDR) detects heterogeneity in residual values; large values may signify oscillations, which are undesirable. The mean squared residual (MSR) value reveals locally high deviations in the curve; high MSR value relative to the MAR value usually signifies oscillations. The total volume difference (TVD) calculated for the whole stem expresses the absolute difference between volume calculated from the spline model and volume assessed from real measured diameters. Both the volume of spline models and volume of stems were calculated as the sum of the particular volumes of $\log$ sections using Smalians equation. To determine the effect of individual splines, values of each evaluative criterion were inspected using analysis of variance for curves generated with the same number of points. Also the effect of input point number was determined for each evaluative criterion using analysis of variance separately for each spline type. Programs for computing separate splines were written in MATLAB version R2012b (The MathWorks, Inc.), which was also used for statistical evaluation.

\section{Results}

Based on preliminary analyses, interpolation B-splines of degree 3 and 4 (IBS3, IBS4) were excluded because they generated uncontrollable oscillations. Approximation splines of degree 4 (BS4, NUBS4, NURBSdbh4, NURBSav4) were removed from subsequent analysis because of their low forming ability.

\section{The influence of input point number}

The accuracy of spline stem curve models improved with an increase in the number of input points up to a threshold number. As il- 
Table 2 Optimal combinations of input points for particular point numbers (Figueiredo-Filho et al. 1996)

\begin{tabular}{ll}
\hline Combination no. & Relative height (\%) \\
1 & 15,35 \\
2 & $15,45,75$ \\
3 & $10,25,45,65$ \\
4 & $10,25,45,65,85$ \\
5 & $10,25,35,45,65,85$ \\
6 & $10,15,25,45,65,85,95$ \\
7 & $10,15,25,35,45,65,85,95$ \\
8 & $10,15,25,35,45,55,65,85,95$ \\
9 & $10,15,25,35,45,55,65,75,85,95$ \\
\hline
\end{tabular}

Table 3 Statistical criteria used for evaluating the accuracy of the models

\begin{tabular}{|c|c|c|}
\hline Sign & Statistical criterion & Calculation \\
\hline DB & Diameter bias & $\Sigma \operatorname{Diff}_{i} / N$ \\
\hline MAR & Mean absolute residual & $\Sigma a b s\left(\operatorname{Diff}_{i}\right) / N$ \\
\hline SDR & Standard deviation of residuals & $\Sigma\left[\left(\text { Diff }_{-}-D B\right)^{2} /(N-1)\right]^{0.5}$ \\
\hline MSR & Mean squared residual & $\Sigma(\text { Diff })^{2} / N$ \\
\hline VD & Volume difference & $V_{s p l}-V_{\text {orig }}$ \\
\hline $\operatorname{Diff}_{i}$ & \multicolumn{2}{|c|}{ Difference between predicted and measured diameter } \\
\hline $\mathrm{N}$ & \multicolumn{2}{|l|}{ Number of measured diameters } \\
\hline $\mathrm{V}_{\mathrm{spl}}$ & Volume form predicted diameters & $\sum L_{i}\left(\pi d_{i}^{2}+\pi d_{i+1}^{2}\right) / 8$ \\
\hline$V_{\text {origl }}$ & Volume form measured diameters & $\Sigma L_{i}\left(\pi D_{i}^{2}+\pi D_{i+1}^{2}\right) / 8$ \\
\hline$d_{i}$ & \multicolumn{2}{|l|}{ Predicted diameter } \\
\hline $\mathrm{D}_{\mathrm{i}}$ & \multicolumn{2}{|l|}{ Measured diameter } \\
\hline $\mathrm{L}_{\mathrm{i}}$ & \multicolumn{2}{|c|}{ Distance between $\mathrm{i}^{\text {th }}$ and $(\mathrm{i}+1)^{\text {th }}$ diameter } \\
\hline
\end{tabular}

lustrated in Table 4, near maximum accuracy was obtained in almost all cases with nine input points (four input points at fixed positions and five additional points at relative heights); the use of more than nine input points did not result in a statistically significant improvement in accuracy. No significant improvement in accuracy was observed even with the use of the full set of 22 input points (absolute heights 0 $\mathrm{m}, 0.3 \mathrm{~m}, 1.3 \mathrm{~m}$ and relative heights $10 \%, 15$ $\%$. . . $95 \%, 100 \%$ ). Therefore the use of more than 9 input points was not investigated in this study. The effect of numbers of input points is demonstrated with an example based on MAR values obtained with the Catmull-Rom spline
(Figure 2)

\section{Performance of individual splines}

Individual spline types with 6 (the least number investigated; $0 \mathrm{~m}, 0.3 \mathrm{~m}, 1.3 \mathrm{~m}, 15 \%$, $35 \%, 100 \%$ ) and 9 (the highest number meaningful for accuracy improvement; $0 \mathrm{~m}, 0.3 \mathrm{~m}$, $1.3 \mathrm{~m}, 10 \%, 25 \%, 45 \%, 65 \%, 85 \%, 100 \%)$ input points are compared in Tables 5 and 6 . Indication of significant differences among individual spline types is provided according to each criterion. Due to similar behavior of some spline types the number of splines was reduced for visualization of their performance. The it- 
erative B-spline acted similarly as the natural cubic spline but performed worse; therefore only natural cubic spline is visualized. From all approximation splines the best representative (BS2) was selected for visualization. The distribution of residuals of nine-point CatmullRom spline, as well as $2^{\text {nd }}$ degree interpolation B-spline, natural cubic spline and $2^{\text {nd }}$ degree approximation B-spline are shown in Figure 3. While for Catmull-Rom spline and interpola-

Table 4 Numbers of input points sufficient for accurate description of the stem form in terms of the indicated statistic

\begin{tabular}{llllll}
\hline Spline & DB & MAR & SDR & MSR & TVD \\
\hline CRS & 9 & 9 & 9 & 7 & 7 \\
IBSu2 & 9 & 7 & 7 & 7 & 8 \\
NCS & 8 & 8 & 8 & 8 & 8 \\
IterBS & 9 & 8 & 8 & 8 & 8 \\
BS2 & 9 & 9 & 9 & 7 & 9 \\
BS3 & 9 & 9 & 7 & 7 & 9 \\
NUBS2 & 9 & 9 & 9 & 7 & 9 \\
NUBS3 & 9 & 9 & 9 & 9 & 9 \\
NURBSdbh2 & 9 & 9 & 7 & 7 & 9 \\
NURBSdbh3 & 9 & 9 & 9 & 9 & 9 \\
NURBSav2 & 9 & 9 & 9 & 9 & 9 \\
NURBSav3 & 11 & 9 & 9 & 9 & 11 \\
\hline
\end{tabular}

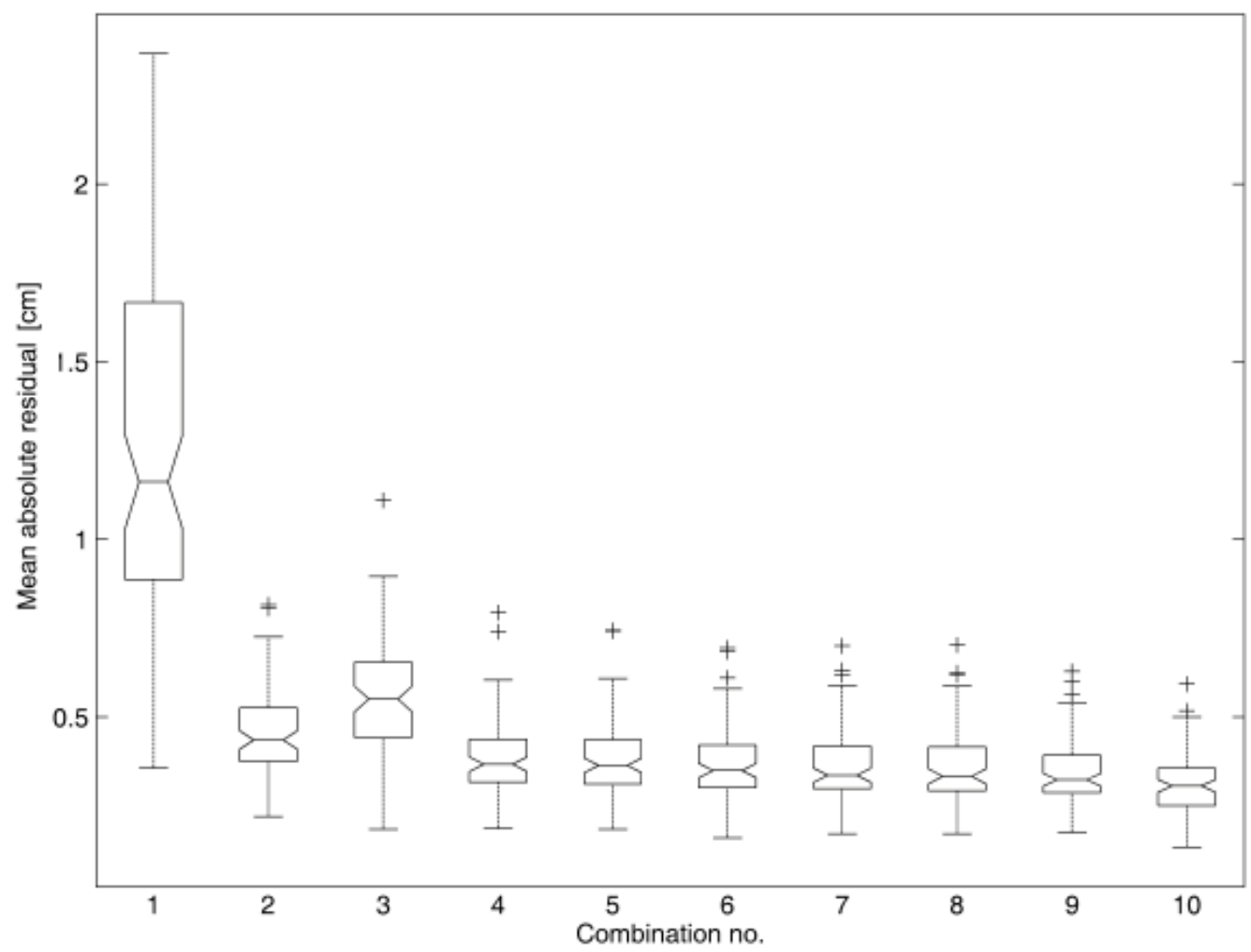

Figure 2Relationship between mean absolute residual (MAR) and number of input points for the CatmullRom spline. Combination no. 10 contains 22 input points, as idicated in the text. Boxes indicate medians and 25th and 75th percentiles; notches indicate comparison intervals for medians; whiskers correspond to $99 \%$ coverage of the data; crosses denote outlier values 
Table 5 Mean values (mean) and standard deviations (SD) of statistics for splines based on six input points

\begin{tabular}{llllllllllllllllll}
\hline \multirow{2}{*}{ Spline } & \multicolumn{1}{c}{ DB $\left(10^{-2} \mathrm{~m}\right)$} & \multicolumn{6}{c}{ MAR $\left(10^{-2} \mathrm{~m}\right)$} & \multicolumn{6}{c}{ SDR $\left(10^{-2} \mathrm{~m}\right)$} & \multicolumn{6}{c}{ MSR $\left(10^{-3} \mathrm{~m}^{2}\right)$} & \multicolumn{3}{c}{ TVD $(\%)$} \\
\cline { 2 - 15 } & mean & SD & sign. & mean & SD & sign. mean & SD & sign. mean & SD & sign. mean & SD & sign. \\
\hline CRS & -1.03 & 0.52 & $\mathrm{a}^{*}$ & 1.30 & 0.54 & $\mathrm{a}, \mathrm{b}$ & 1.64 & 0.69 & $\mathrm{a}, \mathrm{b}$ & 0.32 & 0.26 & $\mathrm{a}$ & -8.22 & 3.69 & $\mathrm{a}^{*}$ \\
IBSu2 & -0.92 & 0.49 & $\mathrm{a}^{*}$ & 1.14 & 0.47 & $\mathrm{a}$ & 1.46 & 0.61 & $\mathrm{a}$ & 0.25 & 0.21 & $\mathrm{a}$ & -8.14 & 3.80 & $\mathrm{a}^{*}$ \\
NCS & 0.44 & 1.03 & $\mathrm{c}^{*}$ & 1.76 & 1.33 & $\mathrm{c}$ & 2.11 & 1.49 & $\mathrm{c}$ & 0.67 & 0.99 & $\mathrm{~b}$ & 6.27 & 11.01 & $\mathrm{~b}^{*}$ \\
IterBS & 0.49 & 1.11 & $\mathrm{c}^{*}$ & 2.26 & 1.74 & $\mathrm{~d}$ & 2.73 & 1.97 & $\mathrm{~d}$ & 1.13 & 1.61 & $\mathrm{c}$ & 7.12 & 12.89 & $\mathrm{~b}^{*}$ \\
BS2 & -1.16 & 0.61 & $\mathrm{a}, \mathrm{b}^{*}$ & 1.57 & 0.61 & $\mathrm{~b}, \mathrm{c}$ & 1.93 & 0.75 & $\mathrm{~b}, \mathrm{c}$ & 0.43 & 0.33 & $\mathrm{a}, \mathrm{b}$ & -9.24 & 4.01 & $\mathrm{a}^{*}$ \\
BS3 & -1.15 & 0.61 & $\mathrm{a}, \mathrm{b}^{*}$ & 1.67 & 0.64 & $\mathrm{~b}, \mathrm{c}$ & 2.02 & 0.77 & $\mathrm{~b}, \mathrm{c}$ & 0.47 & 0.35 & $\mathrm{a}, \mathrm{b}$ & -8.85 & 4.17 & $\mathrm{a}^{*}$ \\
NUBS2 & -1.24 & 0.63 & $\mathrm{a}, \mathrm{b}^{*}$ & 1.61 & 0.63 & $\mathrm{~b}, \mathrm{c}$ & 1.95 & 0.76 & $\mathrm{~b}, \mathrm{c}$ & 0.45 & 0.34 & $\mathrm{a}, \mathrm{b}$ & -10.34 & 4.09 & $\mathrm{a}, \mathrm{c}^{*}$ \\
NUBS3 & -1.28 & 0.65 & $\mathrm{a}, \mathrm{b}^{*}$ & 1.71 & 0.66 & $\mathrm{~b}, \mathrm{c}$ & 2.04 & 0.79 & $\mathrm{~b}, \mathrm{c}$ & 0.48 & 0.37 & $\mathrm{a}, \mathrm{b}$ & -10.83 & 4.31 & $\mathrm{a}, \mathrm{c}^{*}$ \\
NURBSdbh2 & -1.17 & 0.64 & $\mathrm{a}, \mathrm{b}^{*}$ & 1.68 & 0.63 & $\mathrm{~b}, \mathrm{c}$ & 2.08 & 0.77 & $\mathrm{~b}, \mathrm{c}$ & 0.50 & 0.36 & $\mathrm{a}, \mathrm{b}$ & -8.99 & 4.36 & $\mathrm{a}^{*}$ \\
NURBSdbh3 & -1.27 & 0.68 & $\mathrm{a}, \mathrm{b}^{*}$ & 1.83 & 0.68 & $\mathrm{c}$ & 2.20 & 0.80 & $\mathrm{c}$ & 0.55 & 0.39 & $\mathrm{a}, \mathrm{b}$ & -10.30 & 4.94 & $\mathrm{a}, \mathrm{c}^{*}$ \\
NURBSav2 & -1.44 & 0.74 & $\mathrm{~b}^{*}$ & 1.93 & 0.72 & $\mathrm{c}, \mathrm{d}$ & 2.30 & 0.85 & $\mathrm{c}, \mathrm{d}$ & 0.61 & 0.44 & $\mathrm{~b}$ & -12.33 & 4.89 & $\mathrm{c}^{*}$ \\
NURBSav3 & -1.47 & 0.73 & $\mathrm{~b}^{*}$ & 1.90 & 0.73 & $\mathrm{c}, \mathrm{d}$ & 2.22 & 0.86 & $\mathrm{c}$ & 0.57 & 0.43 & $\mathrm{a}, \mathrm{b}$ & -12.98 & 4.76 & $\mathrm{c}^{*}$ \\
\hline
\end{tabular}

Note. Values in a column followed by the same letter (sign.) indicate no significant difference between spline types. Stars in columns DB and TVD indicate mean values significantly different from zero.

Table 6 Mean values and standard deviations of statistics for splines based on nine input points

\begin{tabular}{|c|c|c|c|c|c|c|c|c|c|c|c|c|c|c|c|}
\hline \multirow{2}{*}{ Spline } & \multicolumn{3}{|c|}{$\mathrm{DB}\left(10^{-2} \mathrm{~m}\right)$} & \multicolumn{3}{|c|}{$\operatorname{MAR}\left(10^{-2} \mathrm{~m}\right)$} & \multicolumn{3}{|c|}{$\operatorname{SDR}\left(10^{-2} \mathrm{~m}\right)$} & \multicolumn{3}{|c|}{$\operatorname{MSR}\left(10^{-3} \mathrm{~m}^{2}\right)$} & \multicolumn{3}{|c|}{ TVD (\%) } \\
\hline & mean & SD & sign. & mean & SD & sign. & mean & SD & sign. & mean & $\mathrm{SD}$ & sign. & mean & SD & sign. \\
\hline CRS & 0.00 & 0.15 & $a, b$ & 0.39 & 0.11 & $\mathrm{a}$ & 0.54 & 0.17 & & 0.03 & 0.02 & & 0.25 & 2.17 & \\
\hline $\mathrm{BSu} 2$ & 02 & 0.15 & $a, b$ & 0.43 & 0.12 & & 0.66 & 0.23 & $a, b$ & 0.05 & 0.04 & $a, b$ & -1.27 & 2.52 & \\
\hline NCS & .16 & 0.19 & $\mathrm{c}^{*}$ & 0.70 & 0.32 & & 1.07 & 0.53 & & 0.14 & 0.15 & & -1.68 & 2.51 & $\mathrm{~b}, \mathrm{c}^{*}$ \\
\hline terBS & -0.26 & 0.23 & $d^{*}$ & 0.95 & 0.48 & d & 1.52 & 0.82 & $\mathrm{~d}$ & 0.30 & 0.33 & & -2.89 & 2.77 & $c^{*}$ \\
\hline 3S2 & .01 & 0.17 & $a, b$ & 0.52 & 0.1 & $\mathrm{~b}, \mathrm{e}$ & 0.83 & 0.24 & $\mathrm{~b}$ & 0.07 & 0.04 & $a, b$ & 1.43 & 2.34 & $\mathrm{a}, \mathrm{d}, \mathrm{e}^{*}$ \\
\hline BS3 & -0.02 & 0.19 & $a, b$ & 0.58 & 0.15 & e & 0.93 & 0.29 & $\mathrm{~b}, \mathrm{c}$ & 0.09 & 0.06 & $\mathrm{~b}, \mathrm{c}$ & 1.63 & 2.44 & $\mathrm{~d}, \mathrm{e}^{*}$ \\
\hline NUB & -0.02 & 0.17 & $a, b$ & 0.51 & 0.12 & $\mathrm{~b}, \mathrm{e}$ & 0.80 & 0.23 & & 0.07 & 0.04 & $a, b$ & 1.22 & 2.31 & $\mathrm{a}, \mathrm{d}^{*}$ \\
\hline NUB & -0.04 & 0.20 & $\mathrm{a}^{*}$ & 0.59 & 0.16 & $\mathrm{c}, \mathrm{e}$ & 0.94 & 0.28 & $\mathrm{~b}, \mathrm{c}$ & 0.10 & 0.06 & $\mathrm{~b}, \mathrm{c}$ & 1.39 & 2.47 & $\mathrm{a}, \mathrm{d}^{*}$ \\
\hline NURF & 0.05 & 0.19 & $\mathrm{~b}$ & 0.58 & 0.14 & $\mathrm{e}$ & 1.03 & 0.35 & $\mathrm{c}$ & 0.12 & 0.08 & $\mathrm{~b}, \mathrm{c}$ & 2.64 & 2.77 & $\mathrm{~d}, \mathrm{e}^{*}$ \\
\hline NURF & 02 & 0.22 & $a, b$ & 0.66 & 0.1 & $c, E$ & 1.17 & 0.42 & 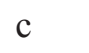 & 0 . & 0.11 & 6 & 2.72 & 3.05 & $\mathrm{~d}, \mathrm{e}^{*}$ \\
\hline & 0.00 & 0.20 & $a, b$ & 0.62 & 0. & $\mathrm{c}, \mathrm{e}$ & 1.07 & 0.35 & & 0.12 & 0.08 & $\mathrm{~b}, \mathrm{c}$ & 2.24 & 2.79 & $\mathrm{~d}, \mathrm{e}^{*}$ \\
\hline NURBSav3 & -0.08 & 0.24 & $\mathrm{a}, \mathrm{c}^{*}$ & 0.69 & 0.20 & $\mathrm{c}$ & 1.06 & 0.34 & $\mathrm{c}$ & 0.12 & 0.08 & $\mathrm{~b}, \mathrm{c}$ & 1.45 & 2.71 & $\mathrm{a}, \mathrm{d}, \mathrm{e}^{*}$ \\
\hline
\end{tabular}

Note. The abbreviations are the same as for Table 5 .

tion B-spline residuals are symmetrically distributed in a narrow interval around zero, the other two splines show residuals of high values and asymmetrical distribution of residuals. The performance of these four selected representatives is shown in Figures 4 and 5.

The only spline that did not show systematic errors in both diameter prediction and volume estimation with more than 6 points was the
Catmull-Rom spline (Figure 4). Moreover, the Catmull-Rom spline together with the second degree interpolation B-spline had the lowest values of MAR, SDR, and MSR. The interpolation B-spline (Figure 4), that exhibits also low diameter errors, systematically underestimated the total volume even with higher numbers of input points.

When six points were used, the natural cu- 


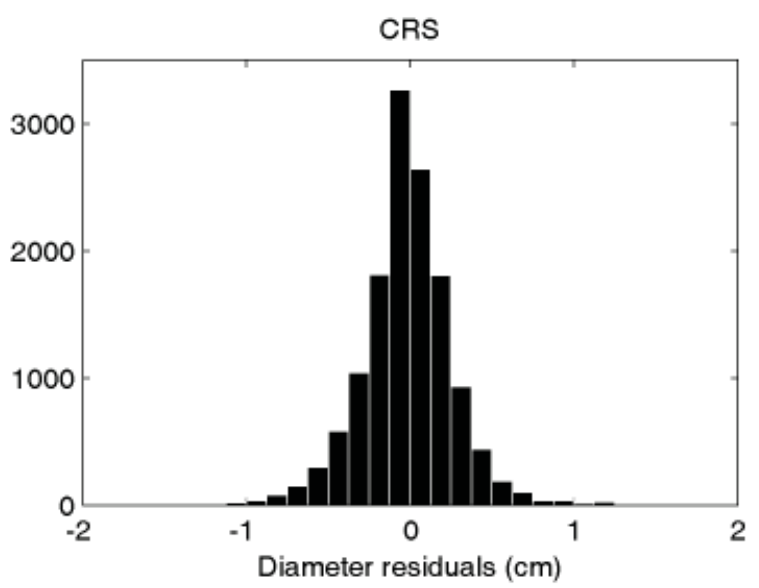

NCS

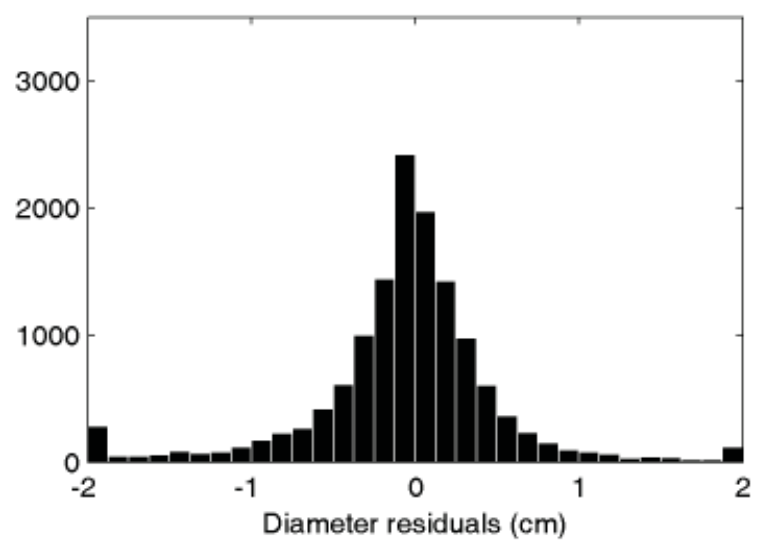

IBS

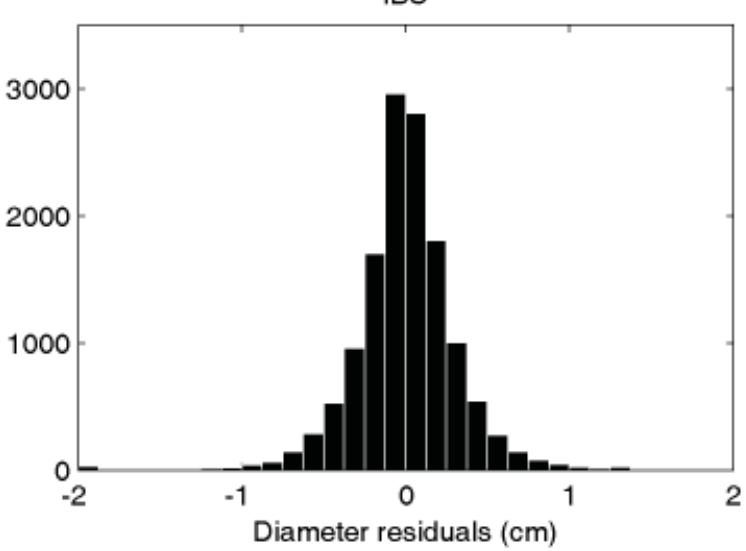

BS

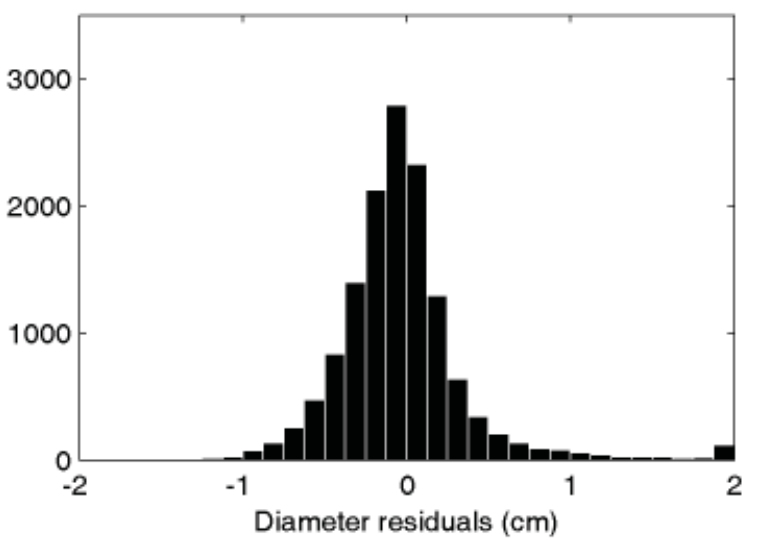

Figure 3 Histograms of diameter residuals of four important splines with 9 input points
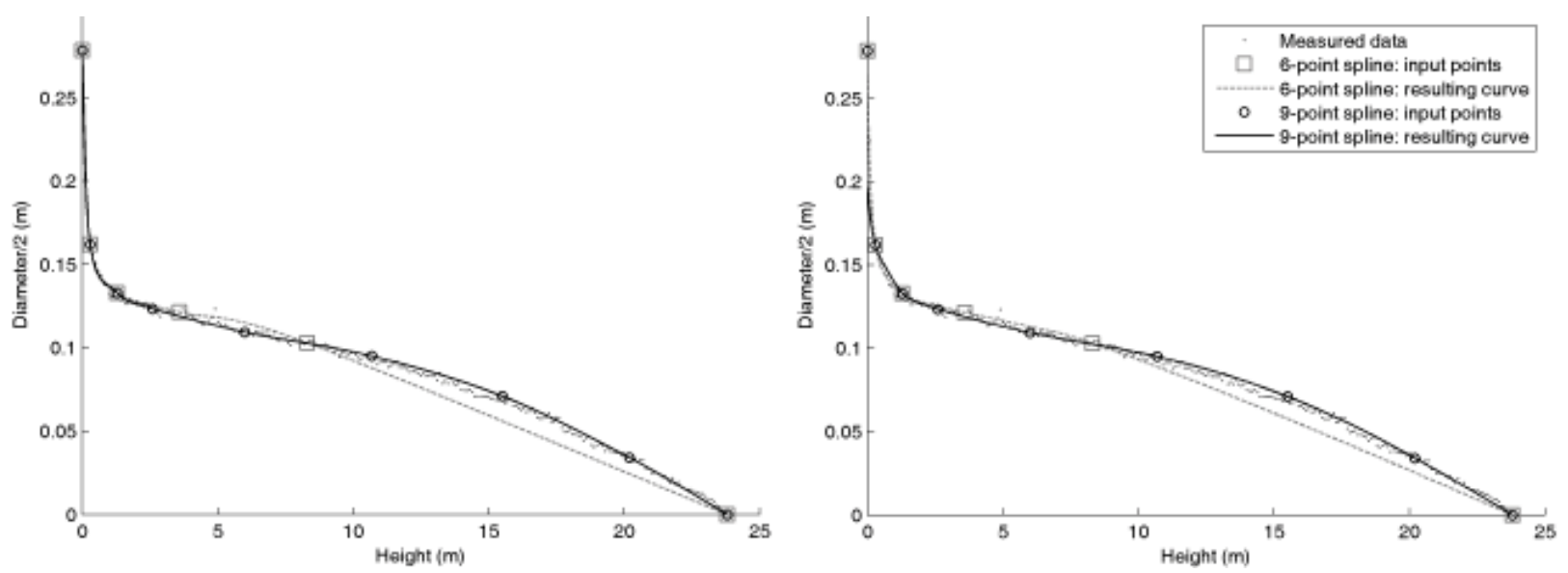

Figure 4 Stem-form curves modeled by the Catmull-Rom spline (left) and $2^{\text {nd }}$ degree interpolation B-spline (right) based on six and nine input points

bic spline (Figure 5) and the iterative B-spline had positive bias and overestimated the stem volume. With seven or more input points, the natural cubic spline and iterative B-spline systematically underestimated the diameters and the total volumes. With six or seven input points, these two spline types had the highest SDR and MSR values among all splines, in- 

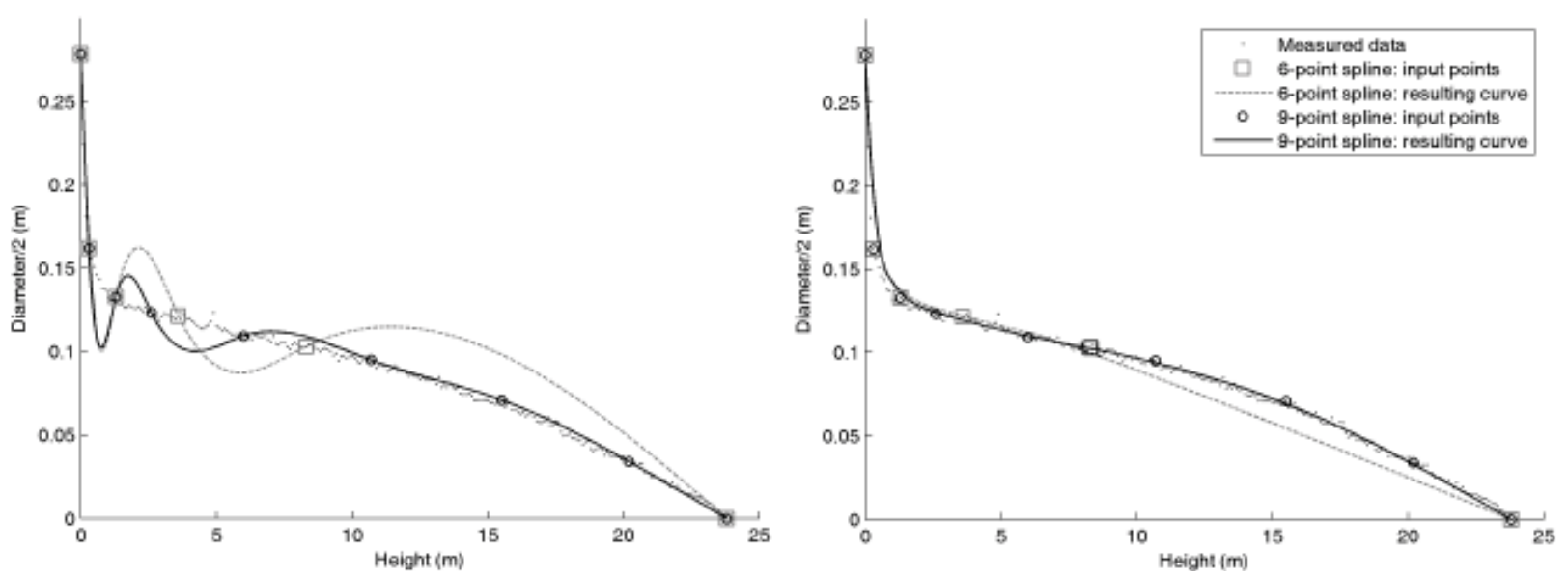

Figure 5 Stem-form curves modeled by the natural cubic spline (left) and 2nd degree Bspline (right) based on six and nine input points

dicating a chance of oscillations; deviations with the iterative B-spline were always higher. The presence of oscillation with the natural cubic spline is also obvious from the display of sectional diameter bias in Figures 6 and 7. With more than seven input points, residuals and their square values were most pronounced with the iterative B-spline while oscillations generated by the natural cubic spline were reduced.

The behavior of all approximation splines was very similar. BS2 was the best representative of the group, and its curves are shown in Figure 5. With an increase in the number of input points, MAR, SDR, and MSR for all the approximation splines decreased, indicating that the fit of the splines to the real stem curve improved. On the other hand, bias values and total volume estimates increased with increasing input points. For input combinations 1-3 (six to eight points), bias was negative, while for more than 11 input points, bias became positive. The TVD value was negative for the smallest number of input points; for more than eight input points, the total volume was significantly overestimated. With the approximation splines, residual values tended to increase (in many cases with statistical significance) with an increase in the spline degree. In addition, residual values were higher for NURBS than for B-splines.

\section{Discussion}

The propensity of the natural cubic spline for oscillations has been described earlier (Lahtinen 1988, Figueiredo-Filho et al. 1996) and is attributed to the continuity of its second derivative. In agreement with (Figueiredo-Filho et al. 1996), oscillation in the current study most often occurred with smaller numbers of input points. The oscillations produced by the iterative B-spline were even higher than those of the natural cubic spline and are easily explained. The natural cubic spline has minimal curvature among all second-order continuous curves interpolating a given set of points (Lahtinen 1988, Liu 1980). Because the iterative B-spline has been proven to approach the interpolation curve (Lin et al. 2004) and has second-order continuity, its curvature must necessarily be higher than that of natural cubic spline, which results in more pronounced oscillations. For the same reasons, oscillations were observed in this study for all interpolation B-splines of the third and fourth degree, which have second and even third, respectively, degree continuity. Because there is no reason to assume that the stem curve is necessarily second-degree continuous, it is better to avoid the risk of oscillation by not using second-degree continuous interpolation splines. This agrees with Lahtinen (1988) who achieved better re- 

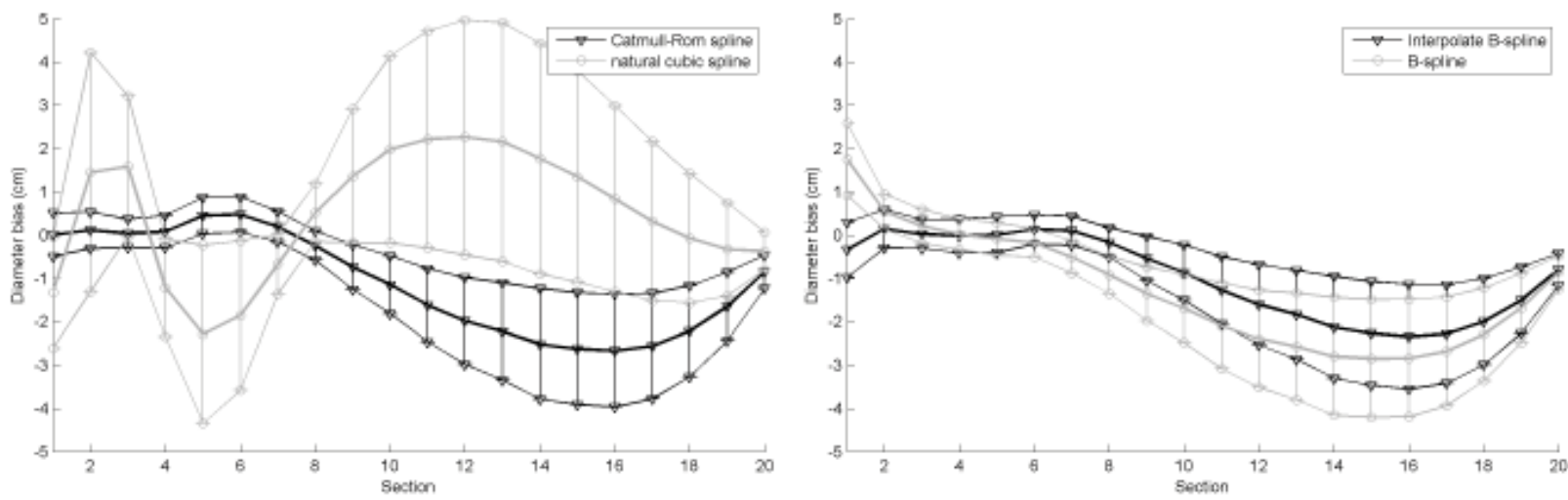

Figure 6 Sectional diameter for four selected six-points splines
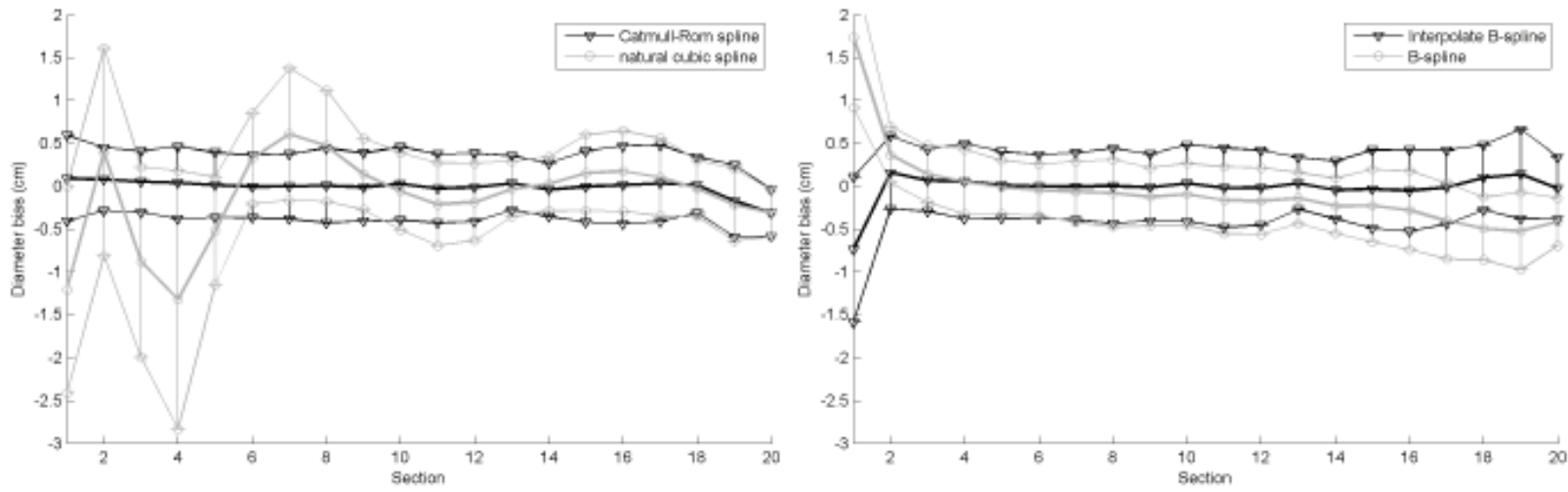

Figure 7 Sectional diameter for four selected nine-points splines

sults using a quadratic spline with only firstdegree continuity.

Error values were higher for approximation splines of the third degree than for those of the second degree, and were even higher for splines of the fourth degree. The poor performance of approximation splines of higher degrees can be explained according to Koskela et al. (2006). The greater the degrees of the Bspline, the more points drive each segment of the curve. Therefore the relative influence of each input point position on the shape of the segment decreases and the distance between the resulting curve and the input points increases. Weight implementation also affects curve accuracy. NURBS that emphasized DBH and that had weights set by the averaging method had higher residual values than the plain B-spline with uniform weight distribution. Weights of the input points in NURBS express the relative importance of the input points. The negative consequence of improving the approach of the curve to the emphasized point is a reduction in how the other points affect the curve. BS2 with uniform knot vector and NUBS2 with averaging knot vector produce very similar results. Therefore, the knot vector does not appear to be crucial.

B-splines and NURBS are always smoother than the driving polygon (MacCallum \& Zhang 1986) and lie within its convex hull. Therefore, the lower part of a stem is always overestimated while the upper part is underestimated. With few input points, all of the splines examined here underestimated the diameters and total volume. An increase in the number of input points improved the representation of the upper stem but not of the butt swell curvature. When the numbers of points were increased, therefore, the upper stem diameter was no longer 
underestimated, and the total values were influenced by the positive deviation at the lower stem. Bias and the volume estimation would be more balanced if more points were also included at the bottom part of the stem.

\section{Conclusions}

Six interpolation splines and twelve approximation splines were selected and their suitability for stem curve representation was evaluated. The natural cubic spline, which has often been used to describe the stem form in forestry research, is inferior to some other splines with respect to the accuracy of the predicted stem curve and to the bias of diameter prediction and of total volume estimation. The best results were obtained with the Catmull-Rom spline, which follows the original data closely, with no oscillation, with well-balanced diameter errors, and with no systematic error in volume prediction. Nearly as well as the Catmull-Rom spline, the interpolation B-spline of second degree can represent stem curves, but the total stem volume calculated with the use of the modeled curve can be underestimated even with higher numbers of input points.

\section{Acknowledgments}

This research was supported by the project of the Ministry of Agriculture of the Czech Republic No. QI102A079.

\section{References}

Biging G.S., 1984. Taper equations for second-growth mixed conifers of Northern California. Forest Science 30: 1103-1117.

Clark N.A., Wynne R.H., Schmoldt D.L., Winn M., 2000. An assessment of the utility of a non-metric digital camera for measuring standing trees. Computers and Electronics in Agriculture 28: 151-169. DOI: 10.1016/ S0168-1699(00)00125-3.

Dean C., 2003. Calculation of wood volume and stem taper using terrestrial single-image close-range photogrammetry and contemporary software tools. Silva Fennica 3: 359-380.

Demaerschalk J.P., 1972. Converting volume equations to compatible taper equations. Forest Science 18: $241-$ 245.

Figueiredo-Filho A., Borders B.E., Hitch K.L., 1996. Number of diameters required to represent stem profiles using interpolated cubic splines. Canadian Journal of Forest Research 26: 1113-1121. DOI: 10.1139/x26-124.

Flewelling J.W., Raynes L.M., 1993. Variable-shape stemprofile predictions for western hemlock. Part I. Predictions from DBH and total height. Canadian Journal of Forest Research 23: 520-536. DOI: 10.1139/x93-070.

Hapca A.I., Mothe F., Leban J.-M., 2007. A digital photographic method for 3D reconstruction of standing tree shape. Annals of Forest Science 64: 631-637. DOI: 10.1051/forest:2007041.

Goulding C.J., Murray J.C., 1976. Polynomial taper equations that are compatible with tree volume equations. New Zealand Journal of Forestry Science 5: 313-322.

Goulding C.J., 1979. Cubic spline curves and calculation of volume of sectionaly measured trees. New Zealand Journal of Forestry Science 9: 89-99.

Jiang L., Brooks J.R., Wang J., 2005. Compatible taper and volume equations for yellow-poplar in West Virginia. Forest Ecology and Management 213: 399-409. DOI: $10.1016 /$ j.foreco.2005.04.006.

Kochanek D.H.U, Bartels R.H., 1984. Interpolating splines with local tension, continuity, and bias control. SIGGRAPH Computer Graphics 18: 33-41. DOI: 10.1145/964965.808575.

Koskela L., Nummi T., Wenzel S., Kivinen V.-P., 2006. On the analysis of cubic smoothing spline-based stem curve prediction for forest harvesters. Canadian Journal of Forest Research 36: 2909-2919. DOI: 10.1139/x06-165.

Lahtinen A., 1988. On the construction of monotony preserving taper curves. Acta Forestalia Fennica 203: $1-34$.

Laasasenaho J., Melkas T., Aldén S., 2005. Modelling bark thickness of Picea abies with taper curves. Forest Ecology and Management 206: 35-47. DOI: 10.1016/ j.foreco.2004.10.058.

Lin H., Wang G., Dong C., 2004. Constructing iterative non-uniform B-spline curve and surface to fit data points. Science in China Series F 47: 315-331. DOI: 10.1360/02yf0529.

Linkeová I., 2007. NURBS křivky. NeUniformní Racionální B-Spline křivky [NURBS curves. Non-Uniform Rational B-spline curves]. Nakladatelství ČVUT. Praha, 208 p.

Lee W.-K., Seo J.-H., Sonm Y.-M., Lee K.-H., von Gadow K., 2003. Modeling stem profiles for Pinus densiflora in Korea. Forest Ecology and Management 172: 69-77. DOI: 10.1016/S0378-1127(02)00139-1.

Liu C.J., 1980. Log volume estimation with spline approximation. Forest Science 26: 361-369.

Lovell J.L., Jupp D.L.B., Newnham G.J., Culvenor 
D.S., 2011. Measuring tree stem diameters using intensity profiles from ground-based scanning lidar from a fixed viewpoint. ISPRS Jounal of Photogrammetry and Remote Sensing 66: 46-55. DOI: 10.1016/ j.isprsjprs.2010.08.006.

MacCalum K.J., Zhang J.-M., 1986. Curve-smoothing techniques using B-splines. The Computer Journal 29: 564-571. DOI: 10.1093/comjnl/29.6.564.

The MathWorks, Inc. MATLAB and Statistics Toolbox Release 2012b, Nattick, Massachusetts, United States.

Max T.A., Burkhart H.E., 1976. Segmented polynomial regression applied to taper equations. Forest Science, 22: 283-289.

Pfeifer N., Winterhalder D., 2004. Modelling of tree cross sections from terrestrial laser scanning data with freeform curves. International Archives of Photogramme- try, Remote Sensing and Spatial Information Sciences, 8-W2: 76-81.

Piegl L., Tiller W. 1996. The NURBS Book, $2^{\text {nd }}$ ed. Springer-Verlag. Berlin, $646 \mathrm{p}$.

Rojo A., Perales X., Sánchez-Rodríguez F., ÁlvarezGonzález J.G., von Gadow K., 2005. Stem taper functions for maritime pine (Pinus pinaster Ait.) in Galicia (Northwestern Spain). European Journal of Forest Research 124: 177-186. DOI: 10.1007/s10342-005-0066-6.

Smaltschinski T., 1983. Individuelle Baumschaftform und cubische Spline Interpolation [Indivudual taper curve of trees and cubic spline interpolation]. Allgemeine Forstund Jagdzeitung 155: 193-197.

Thomas C.E., Parresol B.R., 1991. Simple, flexible, trigonometric taper equations. Canadian Journal of Forest Research 21: 1132-1137. DOI: 10.1139/x91-157. 